\title{
Central Nervous System Radiation Injury
}

National Cancer Institute

\section{Source}

National Cancer Institute. Central Nervous System Radiation Injury. NCI Thesaurus. Code C161518.

Radiation injury of the central nervous system. 